\title{
Changes of the adenine ribonucleotide content during preimplantation development of mouse embryos in vivo and in vitro
}

\author{
H. Spielmann, Ursula Jacob-Mueller*, Petra Schulz* and \\ Angelika Schimmel*
}

Max von Pettenkofer Institut des Bundesgesundheitsamtes, P.O. Box 3300 13, D-1000 Berlin 33, and

*Institut für Toxikologie und Embryonalpharmakologie der Freien Universität Berlin, Garystr. 5, D-1000 Berlin 33, West Germany

\begin{abstract}
Summary. The amount of ATP, ADP and AMP and also the adenylate energy charge and the ATP/ADP ratio were determined in preimplantation mouse embryos (strain NMRI) in vivo. The ATP content decreased from $0.64 \mathrm{pmol}$ at fertilization to $0.21 \mathrm{pmol}$ in late blastocysts. ADP decreased from $0.1 \mathrm{pmol}$ in the zygote to $0.06 \mathrm{pmol}$ in 4-8-cell embryos and increased again to $0.15 \mathrm{pmol}$ in late blastocysts. AMP changed considerably at the 1-cell and the 2-cell stage and increased from 0.04 to $0.2 \mathrm{pmol}$ between the 4-cell and the late blastocyst stage. These developmental changes between fertilization and implantation result in a continuous decline of the total amount of adenine ribonucleotides (from 0.79 to $0.64 \mathrm{pmol}$ ), of the adenylate energy charge (from 0.87 to 0.45 ) and of the ATP/ADP ratio (from 6.4 to 1.4). In C57BL embryos developing to the 2-cell stage in vivo or in vitro there was a decrease in ATP content, as in NMRI embryos in vivo whereas the ATP content remained unchanged in NMRI embryos during culture to the 2-cell stage (no further development in vitro). In blastocysts cultured for $24 \mathrm{~h}$ in media supporting differentiation during implantation (MEM and NCTC-109) the content of ATP and ADP increased but AMP remained constant. The total adenine ribonucleotide content rose to $1 \mathrm{pmol}$ and the ATP/ADP ratio and adenylate energy charge remained unchanged. After $48 \mathrm{~h}$ of culture in the two media to late blastocysts there was a decrease in ATP, an increase in AMP and a decline in adenylate energy charge and ATP/ADP ratio, as occurs in vivo.
\end{abstract}

\section{Introduction}

A general approach to study the overall metabolic activity of preimplantation embryos is the determination of the concentrations and ratios of the adenine ribonucleotides (ATP, ADP and AMP). The ATP and ADP contents of several stages of preimplantation mouse embryos have been measured by the firefly luciferin assay (Ginsberg \& Hillman, 1973; Quinn \& Wales, 1973a, b). The 1-cell embryo is characterized by a high concentration of ATP which decreases gradually to the blastocyst stage. Most importantly, the ATP/ADP-ratio is very high in the early stages. In this respect, the mouse ovum resembles that of the teleost fish rather than that of the sea urchin or the sea squirt.

The complex shifts in the function of metabolic pathways in the preimplantation embryo may be related to the adenylate energy charge (Atkinson, 1967) defined as (ATP + 0.5 (ADP))/(ATP + ADP + AMP). Since cells in normal growth conditions have control systems that maintain the concentrations of the adenine ribonucleotides within narrow limits, marked changes in the adenylate 
energy charge may reflect environmental stress or growth conditions which are interfering with the normal function of the organism. The adenylate energy charge can range from 0 to 1 ; it is $0.85-0.95$ in active organisms and $0.5-0.6$ in stressed and senescent organisms. The influence of the adenylate energy charge on energy-related enzymes during preimplantation development has not been investigated because determinations of AMP levels have so far been impossible in early mouse embryos.

The sensitivity and specificity of the ATP assay using luciferin luciferase have been increased considerably since purified luciferase became commercially available. Using standardized, purified luciferin agents, we have succeeded in developing a simple and specific assay of ATP, ADP and AMP in single preimplantation mouse embryos (Spielmann, Jacob-Mueller \& Schulz, 1981 ; Moyer \& Handerson, 1983). In the present investigation, we have used this assay system to determine the concentrations of the three adenine ribonucleotides in single preimplantation mouse embryos of different strains and to calculate the adenylate energy charge and ATP/ADP ratios during development in vivo and in vitro. We have particularly studied mice of the C57BL strain which do not exhibit a block of development after the first cleavage division in culture and blastocysts at the time of implantation in vivo and in vitro.

\section{Materials and Methods}

\section{Collection and culture of preimplantation mouse embryos}

NMRI and C57BL mice (Institut für Tierzucht, Universität Hannover, West Germany) were mated overnight and the day of finding of the vaginal plug was called Day 0 of pregnancy. Phosphate-buffered saline (PBS: Whittingham \& Wales, 1969) was used to flush preimplantation embryos from the oviducts (zygotes, 2-cell, 4-cell and 8-cell embryos) or uteri (morulae and blastocysts) of pregnant mice at appropriate times as described previously (Schiffner \& Spielmann, 1976).

In experiments with zygotes, the cumulus cells were removed by a short incubation with hyaluronidase (Boehringer Mannheim, West Germany) dissolved in PBS (150 units/ml). The zygotes were cultured under oil according to Brinster (1963) in Whitten's medium (Whitten, 1971) in a humidified $5 \% \mathrm{CO}_{2}$ in air atmosphere. Krebs-Ringer-bicarbonate solution containing pyruvate (Biggers, Whittingham \& Donahue, 1967) was used in some of the zygote culture experiments.

Morulae and early blastocysts were obtained from the uteri of NMRI mice at 14:00 h on Day 3 of pregnancy and late blastocysts between $06: 00 \mathrm{~h}$ and $08: 00 \mathrm{~h}$ on Day 4 since implantation occurs in this strain at about 10:00 h on Day 4. Early blastocysts can quite successfully be cultured in vitro during implantation in Eagle's minimum essential medium (MEM, Flow Laboratories, U.K.) or in medium NCTC-109 (Microbiological Associates, Frankfurt, West Germany) both supplemented with fetal calf serum (FCS) according to Sherman (1975), while differentiation in Whitten's medium is considerably poorer (Spielmann, Eibs, Jacob-Mueller \& Bischoff, 1978). To study changes in the adenylate ribonucleotide contents more closely at the time of implantation in vivo and in vitro, determinations of ATP, ADP and AMP were performed on freshly collected morulae and early blastocysts (14:00 h, Day 3) and late blastocysts (08:00 h, Day 4) and also on blastocysts after culture for 24 and 48 h (NCTC-109, MEM or Whitten's medium) from the morula and early blastocyst stages (starting at 14:00 h on Day 3).

\section{Determination of adenine ribonucleotides in single preimplantation mouse embryos}

Immediately after flushing from the genital tract, after removal of the cumulus cells from zygotes or after removing the culture dishes from the incubator, the embryos were taken up singly in $10 \mu \mathrm{l}$ Tris-EDTA buffer, transferred to an Eppendorf micro-test tube (volume $1.5 \mathrm{ml}$, Eppendorf 
GmbH, West Germany) and kept frozen in liquid nitrogen. Our assay conditions for the three adenine ribonucleotides in single preimplantation mouse embryos using purified firefly luciferin luciferase (ATP-monitoring reagent, LKB Instruments, Graefelfing, West Germany) have been described in detail by Spielmann et al. (1981). ADP and AMP cannot be measured directly by this assay but have to be calculated by subtracting the average values $(A D P=(A T P+A D P)-A T P)$; $\mathrm{AMP}=(\mathrm{ATP}+\mathrm{ADP}+\mathrm{AMP})-(\mathrm{ATP}+\mathrm{ADP}) . \mathrm{ADP}$ and AMP data are generally given without any standard deviation, since the concentrations are rather low compared to those of ATP and since they are calculated from ATP values. The adenylate energy charge and ATP/ADP ratios were derived from the data on single adenine ribonucleotides. Significance levels were determined by the Wilcoxon test.

\section{Results}

Adenine ribonucleotide content of preimplantation mouse embryos during development in vivo

The results for NMRI embryos between fertilization and implantation are given in Table 1 . The amount of ATP in NMRI embryos decreased between fertilization and implantation. Comparing fertilized and unfertilized 1-cell ova (data not shown in Table 1) there were no differences in ATP content per embryo. A slight but significant decrease in ATP was seen during development from the 1 -cell to the 2 -cell stage $(P<0.001)$ and to 4 -cell and 8-cell embryos $(P<0.001)$. The ATP content remained constant for the next $24 \mathrm{~h}$ (morulae and early blastocysts) and was significantly reduced in late blastocysts just before implantation $(P<0.001)$.

Table 1. Adenine ribonucleotide content (pmol/embryo) in preimplantation mouse embryos during development in vivo (strain NMRI)

\begin{tabular}{lccccccc}
\hline $\begin{array}{c}\text { Development } \\
\text { stage }\end{array}$ & ATP & ATP + ADP & ADP & ATP + ADP + AMP & AMP & AEC* & ATP/ADP* \\
\hline 1-cell & $0.64 \pm 0.08(77)$ & $0.74 \pm 0.09(50)$ & 0.10 & $0.79 \pm 0.10(47)$ & 0.05 & 0.87 & 6.4 \\
2-cell & $0.57 \pm 0.08(76)$ & $0.65 \pm 0.08(57)$ & 0.08 & $0.79 \pm 0.10(44)$ & 0.14 & 0.77 & 7.3 \\
4- and 8-cell & $0.43 \pm 0.04(14)$ & $0.49 \pm 0.06(10)$ & 0.06 & $0.53 \pm 0.07(6)$ & 0.04 & 0.87 & 7.2 \\
$\begin{array}{l}\text { Morula and early } \\
\text { blastocyst }\end{array}$ & $0.43 \pm 0.07(30)$ & $0.55 \pm 0.08(33)$ & 0.12 & $0.68 \pm 0.12(29)$ & 0.13 & 0.72 & 3.6 \\
Late blastocyst & $0.21 \pm 0.08(21)$ & $0.37 \pm 0.11(22)$ & 0.15 & $0.64 \pm 0.11(19)$ & 0.28 & 0.45 & 1.40 \\
\hline
\end{tabular}

Values are mean \pm s.d. for the no. of observations given in parentheses.

* Adenylate energy charge (AEC) and ATP/ADP ratios were calculated from the ATP, ADP and AMP measurements.

ADP values decreased slowly during development from the 1-cell to the 4-cell and 8-cell stage but they increased considerably in morulae and blastocysts. The situation was more complex for AMP. This adenine ribonucleotide increased strongly during the first cleavage division, but a very low amount was found in 4-cell and 8-cell embryos. AMP values were higher again in morulae and early blastocysts. In late blastocysts the amount of AMP per embryo was even higher than the ATP content.

The total adenine ribonucleotide content (ATP + ADP + AMP) remained constant during the first cleavage division, although significant changes of the individual adenine ribonucleotides were obtained, e.g. ATP per embryo. The total amount of adenine ribonucleotides decreased during development from the 2-cell to the 4-cell and 8-cell stage and increased significantly at the early and late blastocyst stages $(P<0.001)$. At implantation, the total amount of adenine ribonucleotides was lower than immediately after fertilization. 
The adenylate energy charge remained fairly constant during preimplantation development of NMRI mouse embryos, but a considerable decrease was found in late blastocysts before implantation. This change was due to the low amount of ATP in late blastocysts. The ATP/ADP ratio did not change up to the 8 -cell stage but then decreased towards implantation.

Changes in the adenine ribonucleotide content during the first cleavage division of mouse embryos in vivo and in vitro

Changes in the adenine ribonucleotide content were compared in 1-cell and 2-cell embryos of NMRI and C57BL mice (Table 2). Embryos of C57BL mice can be cultured in Whitten's medium from fertilization to the blastocyst stage (Biggers, Whitten \& Whittingham, 1971) but NMRI embryos show a block in development at the 2-cell stage (Spielmann, Eibs \& Jacob-Mueller, 1980a). Embryos which are arrested at the 2-cell stage during development in vitro cannot be distinguished, under the light microscope, from normal 2-cell embryos which have developed in vivo. However, they do degenerate in culture during the next $24-48 \mathrm{~h}$. As shown in Table 2, ATP values of C57BL 1-cell embryos were significantly higher than those of NMRI embryos at the same stage $(P<0.001)$. In 2 -cell embryos which had developed in vivo a significantly lower ATP content was found in both strains $(P<0.001)$. The total amount of adenine ribonucleotides remained constant in both strains during the first cleavage division but was slightly higher in 1-cell and 2-cell embryos of the C57BL than of the NMRI strain.

Table 2. Adenine ribonucleotide content (pmol/embryo) in preimplantation mouse embryos of two strains of mice during first cleavage division in vivo and in vitro

\begin{tabular}{lllccccc}
\hline \multirow{2}{*}{ Strain } & Medium & $\begin{array}{c}\text { Developmental } \\
\text { stage }\end{array}$ & ATP & ATP + ADP & ADP & ATP + ADP + AMP & AMP \\
\hline \multirow{2}{*}{ NMRI I In vivo } & 1-cell & $0.64 \pm 0.08(77)$ & $0.74 \pm 0.09(50)$ & 0.10 & $0.79 \pm 0.10(47)$ & 0.05 \\
& In vivo & 2-cell & $0.57 \pm 0.08(76)$ & $0.65 \pm 0.08(54)$ & 0.08 & $0.790 \pm 0.10(44)$ & 0.14 \\
\cline { 2 - 8 } & Whitten's & 2-cell & $0.63 \pm 0.07(62)$ & $0.70 \pm 0.07(54)$ & 0.07 & $0.78 \pm 0.07(47)$ & 0.08 \\
& Pyruvate & 2-cell & $0.65 \pm 0.07(50)$ & $0.73 \pm 0.08(43)$ & 0.08 & $0.87 \pm 0.08(42)$ & 0.14 \\
\hline C57BL & In vivo & 1-cell & $0.74 \pm 0.11(24)$ & $0.81 \pm 0.10(20)$ & 0.07 & $0.83 \pm 0.07(14)$ & 0.02 \\
& In vivo & 2-cell & $0.64 \pm 0.06(18)$ & $0.73 \pm 0.03(14)$ & 0.09 & $0.82 \pm 0.08(12)$ & 0.09 \\
\cline { 2 - 7 } & Whitten's & 2-cell & $0.67 \pm 0.06(21)$ & $0.75 \pm 0.08(21)$ & 0.08 & $0.84 \pm 0.09(17)$ & 0.09 \\
& Pyruvate & 2-cell & $0.67 \pm 0.08(12)$ & $0.75 \pm 0.06(15)$ & 0.08 & $0.83 \pm 0.06(14)$ & 0.08 \\
\hline
\end{tabular}

Values are mean $\pm \mathbf{s . d}$. for the no. of observations in parentheses.

The ATP, ADP and AMP contents of C57BL embryos which were cultured in Whitten's medium or in a pyruvate medium (Biggers et al., 1967) were identical to those of C57BL embryos developing in vivo. NMRI 2-cell embryos, however, after culture from the 1-cell stage in the same media, did not show any changes in the three adenine ribonucleotides. Apparently, the significant decrease in ATP content that is characteristic for the first cleavage division in vivo did not occur in NMRI embryos in vitro. Such 2-cell embryos were blocked in further development in culture while 2-cell embryos of the C57BL strain showed identical ATP, ADP and AMP values both in vivo and in vitro. Calculations of the adenylate energy charge and ATP/ADP-ratio for embryos at the 1-cell and 2-cell stages did not give any further information and are therefore not given in Table 2 .

Adenine ribonucleotide content of early and late mouse blastocysts (strain NMRI) developing in vivo and in vitro

Adenine ribonucleotide contents were measured in single mouse blastocysts after culture for 24 and $48 \mathrm{~h}$ in NCTC-109, MEM or Whitten's medium from the morula and early blastocyst stage and 
compared to the data obtained for morulae and early blastocysts and for late blastocysts in vivo (Table 3). None of the three adenine ribonucleotides was detectable in $10 \mu$ l of each of the culture media. The results obtained for blastocysts cultured in Whitten's medium for $24 \mathrm{~h}$ showed a slight increase during the culture period. In morulae and early blastocysts cultured for $48 \mathrm{~h}$ in Whitten's medium the absolute adenine ribonucleotide content was slightly different from that in late blastocysts developing in vivo but the relative changes were comparable to those in vivo.

Table 3. Adenine ribonucleotide content (pmol) of mouse blastocysts before implantation in vivo and in vitro

\begin{tabular}{llccccccc}
\hline \multicolumn{1}{c}{ Medium } & $\begin{array}{c}\text { Blastocyst } \\
\text { stage* }\end{array}$ & ATP & ATP + ADP & ADP & $\begin{array}{c}\text { ATP + ADP } \\
\text { + AMP }\end{array}$ & AMP & AEC ATP/ADP \\
\hline $\begin{array}{lllllll}\text { In vivo } \\
\text { In vivo }\end{array}$ & Early & $0.43 \pm 0.07(30)$ & $0.55 \pm 0.12(33)$ & 0.12 & $0.68 \pm 0.12(29)$ & 0.13 & 0.72 & 3.58 \\
\hline 24 h Whitten's & Eate & $0.21 \pm 0.08(23)$ & $0.36 \pm 0.11(22)$ & 0.15 & $0.64 \pm 0.11(19)$ & 0.28 & 0.45 & 1.40 \\
48 h Whitten's & Late & $0.39 \pm 0.09(72)$ & $0.56 \pm 0.08(66)$ & 0.17 & $0.68 \pm 0.11(70)$ & 0.12 & 0.71 & 2.29 \\
24 h MEM & Early & $0.71 \pm 0.15(47)$ & $0.86 \pm 0.14(44)$ & 0.15 & $0.95 \pm 0.18(41)$ & 0.09 & 0.83 & 4.73 \\
48 h MEM & Late & $0.36 \pm 0.14(31)$ & $0.54 \pm 0.15(24)$ & 0.18 & $0.84 \pm 0.10(37)$ & 0.30 & 0.54 & 2.00 \\
\hline 24 h NCTC-109 & Early & $0.74 \pm 0.13(60)$ & $0.94 \pm 0.16(65)$ & 0.20 & $1.07 \pm 0.16(48)$ & 0.13 & 0.79 & 3.70 \\
48 h NCTC-10: & Late & $0.34 \pm 0.11(49)$ & $0.51 \pm 0.18(50)$ & 0.17 & $0.83 \pm 0.17(29)$ & 0.32 & 0.52 & 2.00 \\
\hline
\end{tabular}

Values are mean \pm s.d. for the no. of observations in parentheses.

* See text.

In contrast, morulae and early blastocysts cultured for $24 \mathrm{~h}$ in MEM or NCTC-109 showed a significant increase in the amount of ATP per embryo. In these blastocysts ADP and AMP changed only slightly. The considerable increase in total adenine ribonucleotide content up to 1 pmol per blastocyst was, therefore, caused by the increase in ATP. These changes in adenine ribonucleotide content moderately affected the adenylate energy charge and the ATP/ADP ratio. Blastocysts cultured for an additional $24 \mathrm{~h}$ (total culture period $48 \mathrm{~h}$ ) in MEM or NCTC-109 showed adenine ribonucleotide contents that were higher than those seen before implantation in late blastocysts in vivo. During the second 24-h culture period the ATP content in late expanded blastocysts decreased significantly (about $50 \%$ ), but there were only slight changes in ADP and the AMP content increased by a factor of 3 to $0.30 \mathrm{pmol}$. The absolute ADP and AMP values were quite similar in late blastocysts before implantation both in vivo and in vitro in all media tested, and the ATP values were higher in MEM and NCTC-109 than in vivo and in Whitten's medium.

The total adenine ribonucleotide content remained constant in vivo during development from the early to the late blastocyst stage. However, in morulae and early blastocysts cultured for $48 \mathrm{~h}$ in Whitten's medium, in MEM or in NCTC-109 an increase in total adenine ribonucleotide content was found. At the same time a decrease in the adenylate energy charge and ATP/ADP ratio was seen in blastocysts before implantation in vivo and in vitro. The significant difference in adenine ribonucleotide content in blastocysts cultured in media which allow differentiation during implantation (MEM and NCTC-109) and in a medium that did not support further differentiation (Whitten's medium) seemed to be related to the considerable increase in ATP content in embryos cultured for $24 \mathrm{~h}$ in MEM and NCTC-109. Similar changes could not be detected in blastocysts developing in vivo. No morphological differences were found under the light microscope in the three groups of cultured blastocysts during the first $24 \mathrm{~h}$ in culture. 


\section{Discussion}

A highly sensitive luciferin luciferase assay (Spielmann et al., 1981; Moyer \& Handerson, 1983) allowed the determination of the three adenine ribonucleotides in single preimplantation mouse embryos. Our data on ATP and ADP contents in preimplantation mouse embryos developing in vivo are comparable to results reported by others using a less sensitive luciferase assay (Quinn \& Wales, 1971; 1973a, b; Epstein \& Daentl, 1971; Ginsberg \& Hillman, 1973). The present investigation is the first report on AMP in preimplantation mouse embryos using the luciferase method. Our AMP data are different from those determined enzymically in preimplantation embryos (Barbehenn, Wales \& Lowry, 1978).

In the present study on NMRI mice the total adenine ribonucleotide content decreased slightly during preimplantation development. The ATP/ADP ratio and the adenylate energy charge remained constant in cleavage stage embryos, although both decreased in late blastocysts at implantation. This was due to the significant decrease in ATP and to the significant increase in AMP in blastocysts before implantation. Similar changes were observed in perfused rat livers when the flow rate was systematically reduced (Iles, Baron \& Cohen, 1979). A comparable decrease in oxygen concentration in the uterine fluid during late preimplantation development may induce both the observed changes in adenine ribonucleotide content and the increase in glycolytic activity that were found in late mouse blastocysts before implantation (Barbehenn et al., 1978). In our determinations of the adenine ribonucleotide content in NMRI and C57BL mouse embryos at the 1-cell and 2-cell stage we observed significant differences during development in vivo and in vitro. The 2-cell embryos of the two strains which had developed in vitro seemed morphologically viable. However, in 2-cell embryos of NMRI mice the decrease in ATP and the increase in AMP, which are characteristic for this stage of development in vivo, were never found in vitro and the embryos were arrested in development. In C57BL 2-cell embryos developing in vivo or in vitro no differences in adenine ribonucleotide content were seen and there was no developmental block at the 2-cell stage in culture. When studying the same problem with a less sensitive assay system Quinn \& Wales (1973b) did not find any differences in ATP levels in a strain of randomly bred albino mice which exhibited the developmental block in vitro or in $F_{1}$ hybrid C57BL $\times$ CBA embryos which can be cultured from fertilization to the blastocyst stage.

The so-called "in-vitro block" in 2-cell embryos can be overcome in some strains of mice by injecting small amounts of cytoplasm from embryos of strains that do not exhibit the developmental block (Muggleton-Harris, Whittingham \& Wilson, 1982). These data suggest that the regulation of the embryonic genome may be controlled by factors in the embryonic cytoplasm. Further studies will elucidate to which extent differences in the genetic background of various strains of mice are related to differences in adenine ribonucleotide contents as observed in the present study.

In mouse blastocysts that were cultured in vitro from the morula and early blastocyst stage we observed a significant increase in ATP content during the first $24 \mathrm{~h}$ in MEM and NCTC-109 but not in Whitten's medium. Similarly, Quinn \& Wales (1973a) found that the amount of ATP in cultured blastocysts was significantly higher than in freshly collected blastocysts. The absolute ATP and ADP values and, consequently, the ATP/ADP ratio of cultured blastocysts in the study of Quinn \& Wales (1973a) are also comparable to our results.

In the MEM and NCTC-109 media which support differentiation of mouse blastocysts before and during early implantation, we not only found an increase in ATP but also a significant increase in the total amount of adenine ribonucleotides during the first $24 \mathrm{~h}$ in culture. Neither medium contained any adenine ribonucleotides and these results may therefore suggest that in-vitro development of blastocysts is only successful if the medium allows an increased synthesis of adenine ribonucleotides. This seems possible since the activity of adenine-phosphoribosyltransferase in freshly collected and cultured mouse embryos increases as development proceeds (Epstein, 1970). The decrease in ATP and the increase in AMP occurring before implantation in vivo were also found in all media tested and may, therefore, be essential for implantation. In all 
media used for the culture of morulae and early blastocysts the whole process of blastocyst growth and expansion takes about $48 \mathrm{~h}$ whereas the same developmental step is completed within $24 \mathrm{~h}$ in vivo (Spielmann, Jacob-Mueller \& Beckford, 1980b). Since we never observed a similar surge in ATP between the early and late blastocyst stage in vivo, the present data may indicate that differentiation of mouse blastocysts in vitro at the time of implantation is accompanied by changes in the adenine ribonucleotide contents that are not characteristic for normal development in vivo.

The preimplantation mouse embryos exhibited fairly constant values for the adenylate energy charge and ATP/ADP ratios, in a range which has been found in other mammalian tissues (Atkinson, 1967; Iles et al., 1979). The only exception was the late blastocyst stage in which the values declined to unusually low values. The adenylate energy charge and the ATP/ADP ratio are, therefore, valuable indicators for the characterization of energy metabolism in early mammalian embryos.

The present investigation was supported by a grant of the Deutsche Forschungsgemeinschaft awarded to the Sonderforschungsbereich 29 "Embryonale Differenzierung und Entwicklung". We thank Dr Ch. Krueger (M. v. Pettenkofer Inst. of the Bundesgesundheitsamt) for useful discussion.

\section{References}

Atkinson, D.E. (1967) Biological feedback control at the molecular level. Biochemistry, N.Y. 7, 4030-4034.

Barbehenn, E.K., Wales, R.G. \& Lowry, O.H. (1978) Measurement of metabolites in single preimplantation embryos: a new means to study metabolic control in early embryos. J. Embryol. exp. Morph. 43, 29-46.

Biggers, J.D., Whittingham, D.G. \& Donahue, R.P. (1967) The pattern of energy metabolism in the mouse oocyte and zygote. Proc. natn. Acad. Sci. U.S.A. 58, 560-563.

Biggers, J.D., Whitten, W.K. \& Whittingham, D.G. (1971) The culture of mouse embryos in vitro. In Methods in Mammalian Embryology, pp. 86-116. Ed. J. C. Daniel, Jr. W. H. Freeman, San Francisco.

Brinster, R.L. (1963) A method for in vitro cultivation of mouse ova from two-cell to blastocyst. Expl Cell Res. 32, 205-208.

Epstein, C.J. (1970) Phosphoribosyltransferase activity during early mammalian development. J. biol. Chem. 245, 3289-3292.

Epstein, C.J. \& Daentl, D.L. (1971) Precursor pools and RNA synthesis in preimplantation mouse embryos. Devl Biol. 26, 517-524.

Ginsberg, L. \& Hillman, N. (1973) ATP metabolism in cleavage stage mouse embryos. J. Embryol. exp. Morph. 30, 267-287.

Iles, R.A., Baron, P.G. \& Cohen, R.D. (1979) The effect of reduction of perfusion rate on lactate and oxygen uptake, glucose output and energy supply in the isolated perfused liver of starved rats. Biochem. $J$. 184, 635-642.

Moyer, J.D. \& Handerson, J.F. (1983) Nucleotide triphosphate specificity of firefly luciferase. Analyt. Biochem. 131, 187-189.

Muggleton-Harris, A., Whittingham, D.G. \& Wilson, L. (1982) Cytoplasmic control of preimplantation development in vitro in the mouse. Nature, Lond. 299, 460-462.

Quinn, P. \& Wales, R.G. (1971) Adenosine triphosphate content of preimplantation mouse embryos. $J$. Reprod. Fert. 25, 133-135.
Quinn, P. \& Wales, R.G. (1973a) The effect of culture in vitro on the levels of adenosine triphosphate in preimplantation mouse embryos. J. Reprod. Fert. 32, 231-241.

Quinn, P. \& Wales, R.G. (1973b) The relationships between the ATP content of preimplantation mouse embryos and their development in vitro during culture. J. Reprod. Fert. 35, 301-309.

Schiffner, J. \& Spielmann, H. (1976) Fluorometric assay of the protein content of mouse and rat embryos during preimplantation development. J. Reprod. Fert. 47, 145-147.

Sherman, M.I. (1975) Long term culture of cells derived from mouse blastocysts. Differentiation 3, 51-67.

Spielmann, H., Eibs, H.G., Jacob-Mueller, U. \& Bischoff, R. (1978) Expression of lactate dehydrogenase isozyme 5 (LDH-5) in cultured mouse blastocysts in the absence of implantation and outgrowth. Biochem. Genet. 16, 191-202.

Spielmann, H., Eibs, H.G. \& Jacob-Mueller, U. (1980a) In vitro methods for the study of the effects of teratogens on preimplantation embryos. Acta morph. hung. 28, 105-115.

Spielmann, H., Jacob-Mueller, U. \& Beckford, W. (1980b) Immunosurgical studies on inner cell mass development in rat and mouse blastocysts before and during implantation in vitro. J. Embryol. exp. Morph. 60, $255-269$.

Spielmann, H., Jacob-Mueller, U. \& Schulz, P. (1981) Simple assay of 0.1-1.0 pmol of ATP, ADP and AMP in single somatic cells using purified luciferin luciferase. Analyt. Biochem. 113, 172-178.

Whitten, W.K. (1971) Nutrient requirements for the culture of preimplantation embryos in vitro. $A d v$. Biosci. 6, 129-141.

Whittingham, D.G. \& Wales, R.G. (1969) Storage of twocell mouse embryos in vitro. Aust. J. biol. Sci. 22, 1065-1068.

\section{Received 18 October 1983}

